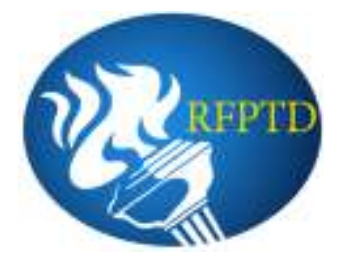

\title{
O ENFRENTAMENTO DAS MATÉRIAS TRIBUTÁRIAS EM ICMS PELO SUPREMO TRIBUNAL FEDERAL E A GUERRA FISCAL* THE FACING OF TAX MATTERS IN ICMS BY THE SUPREME FEDERAL COURT AND THE TAX WAR
}

\author{
Karoline Freire Oliveira** \\ Octávio Campos Fischer***
}

\begin{abstract}
RESUMO: O artigo perspectiva analisar questões que são suscitadas ao Supremo Tribunal Federal em matéria de ICMS e a guerra fiscal que é enfrentada em relação a este tributo. Além de realizar apontamentos gerais em relação à compreensão do vínculo da Suprema Corte do Brasil com as controvérsias jurídicas no âmbito da guerra fiscal do ICMS, também objetivou visualizar a exigência de convênio nos termos da Lei Complementar n. 24/1975, partir do posicionamento do STF, bem como demonstrar os conflitos relativos à exigência de unanimidade para concessão de benefícios fiscais em ICMS.
\end{abstract}

Palavras-chave: ICMS; Guerra Fiscal; Supremo Tribunal Federal.

ABSTRACT: The article prospects to analyze issues that are raised to the Federal Supreme Court regarding ICMS and the fiscal war that is faced in relation to this tax. In addition to making general notes regarding the understanding of the Brazilian Supreme Court's tie with the legal controversies in the scope of the ICMS tax war, it also aimed to analyze the requirement of an agreement under the terms of Complementary Law n. 24/1975, based on the analysis of the position of the Supreme Court, as well as to demonstrate the conflicts regarding the unanimity requirement for the granting of ICMS.

Keywords: ICMS; Tax War; Federal Supreme Court.

\section{INTRODUÇÃO}

O objetivo central deste artigo é enfrentar a relação de discurso entre a atuação do Supremo Tribunal Federal (STF) e o conflito federativo denominado 'guerra fiscal', o qual pode ser entendido pela licença desordenada de incentivos fiscais na Lei Complementar 87/1996, a qual dispõe sobre as deliberações do imposto sobre operações relativas à circulação de mercadorias e prestação

\footnotetext{
*Artigo submetido em 19 fev. 2019 e aceito para publicação em 30 jun. 2019. Publicado em 30 jul. 2019.

** Mestranda em Direitos Fundamentais e Democracia pelo Centro Universitário Autônomo do Brasil (UniBrasil), Curitiba, Paraná, Brasil / karolinef2904@gmail.com

*** Doutor em Direito Tributário pela Universidade Federal do Paraná e Professor de Direito Tributário do Centro Universitário Autônomo do Brasil (UniBrasil), Curitiba, Paraná, Brasil / octaviofischer@uol.com.br
} 
de serviços (ICMS), em relação aos Estados e ao Distrito Federal, com olhares à inferência de investimentos privados. O confronto vincula diversas regiões do Brasil e tem cabimento constitucional. Por diversos anos questões vinculadas ao ICMS são constantes nas análises jurisdicionais realizadas pelo STF sem ter, entretanto, esta Corte Suprema chegado à resolução satisfatória.

Historicamente, a Corte Maior é convocada a se pronunciar em relação a programas de incentivo fiscal planeados unilateralmente pelos Estados ou pelo Distrito Federal, em desconcerto com os ritos e requisitos constitucionais impostos para essas diligências.

Embora haja um concreto posicionamento na jurisprudência do STF, o conflito federativo continua e acentua-se na proporção das urgências econômicas e dos interesses políticos regionais.

A finalidade deste texto é examinar o trabalho do Supremo Tribunal Federal diante deste quadro, por meio de uma análise dos indispensáveis questionamentos ocasionados na seara da Corte Magna, tanto no que se refere ao controle abstrato quanto em relação ao controle concreto. Objetivase, portanto, indicar um panorama atual da guerra fiscal no STF, examinando a linha de orientação adotada, nos casos já solucionados, bem como as predominantes controvérsias que estão em pauta para serem decididas pela Corte.

O método empregado para elaboração deste artigo foi o dedutivo através de pesquisa na base de dados públicos do Supremo Tribunal Federal, para os casos submetidos à sistemática da repercussão geral ainda não julgados. Especulando-se também as ações de controle abstrato em tramitação.

A estruturação deu-se em três capítulos, tendo o primeiro a finalidade de expor apontamentos essenciais à compreensão da 'Guerra Fiscal'; cabendo ao segundo capítulo enfatizar as controvérsias jurídicas no âmbito da guerra fiscal do ICMS e a exigência de convênio nos termos da Lei Complementar n. 24/1975, a partir da análise do posicionamento do STF; e, finalmente, cuidou o terceiro capítulo de demonstrar a exigência de unanimidade para concessão de benefícios fiscais em ICMS e o embate do Supremo Tribunal Federal com a doutrina contemporânea em relação à matéria.

O resultado da pesquisa tem caráter qualitativo, sem o objetivo de considerar o exaustivo rol e pretensamente completo de todos os casos julgados ou em tramitação no Supremo Tribunal Federal em relação à temática, senão indicar as questões ainda em aberto e as diretrizes de precedentes firmadas até o presente momento. 


\section{A GUERRA FISCAL E SUAS PARTICULARIDADES EM RELAÇÃO AO ICMS}

A guerra fiscal pode ser compreendida como um quadro de emulação tributária predatória, na qual os Estados e o Distrito Federal valem-se da concessão de benesses fiscais, por meio da lei que regula o imposto sobre operações relativas à circulação de mercadorias e prestação de serviços, para magnetizar ou manter investimentos privados em seus territórios.

Ocupa-se, especialmente, de uma batalha fiscal entre os entes federados, que utilizam instrumentos tributários, popularmente denominados de 'benefícios fiscais', objetivando o favorecimento tributário de relativa parcela de contribuintes ou segmento econômico ${ }^{1}$.

Nesta perspectiva, válidas as lições de Luiz Gurgel de Faria²:

A expressão guerra fiscal retrata uma situação de disputa econômica entre entes autônomos, possuidores de competência tributária, que visam obter para seus respectivos territórios um determinado empreendimento econômico, oferecendo, para tanto, benefícios para atrair pessoas interessadas, sejam vantagem de ordem tributária ou de outra natureza, como infraestrutura, capacitação de recursos humanos, disponibilização de crédito a menor custo, dentre outras.

O fenômeno da guerra fiscal não atinge unicamente o ICMS, mas abrange outros impostos, tais quais, o IPVA (Imposto sobre Propriedade de Veículos Automotores) e o ISSQN (Imposto sobre Serviços de Qualquer Natureza), sendo de cada qual dessas categorias de impostos possuem suas peculiaridades, chegando à análise do Supremo Tribunal Federal.

Um visível exemplo é a decisão proferida na $\mathrm{ADPF}^{3}$ 190, na qual se debatia a inconstitucionalidade da Lei Municipal de Poá, no estado de São Paulo, que reduziu a base de cálculo do ISSQN em seu território. A tese adotada pela Corte Maior foi a de que é inconstitucional lei municipal que veicule exclusão de valores da base de cálculo do ISSQN fora das hipóteses previstas em lei complementar nacional, sendo também incompatível com o texto constitucional medida fiscal que resulte indiretamente na redução da alíquota mínima, por meio da redução da carga tributária incidente sobre a prestação de serviço na territorialidade do ente tributante ${ }^{4}$.

Outro caso ilustrativo foi o que ganhou reconhecimento de repercussão geral no acórdão 784.682, de relatoria do Ministro Marco Aurélio, em que se discute o local de pagamento do IPVA

\footnotetext{
${ }^{1}$ CORREIA NETO, Celso de Barros. O avesso do tributo. 2 ed. São Paulo: Almedina, 2016, p. 131 - 132.

${ }^{2}$ FARIA, Luiz Alberto Gurgel de. A extrafiscalidade e a concretização do princípio da redução das desigualdades regionais. São Paulo: QuartierLatin, 2010, p. 129.

${ }^{3}$ Sigla para: Arguição de descumprimento de preceito fundamental.

${ }^{4}$ BRASIL Supremo Tribunal Federal. Arguição de Descumprimento de Preceito Fundamental n. 190. Relator: Ministro Edson Fachin. DJ. 12.05.2017.
} 
"se em favor do Estado no qual se encontra sediado ou domiciliado o contribuinte ou onde registrado e licenciado o veículo automotor cuja propriedade constitui fato gerador do tributo"5.

Porém, ainda que ocorram discussões em relação a outros tributos, aquele que ganha maior notoriedade e é o protagonista da guerra fiscal no Brasil - seja pela perda de arrecadação, seja pelos demais efeitos econômicos que enseja - é o que se efetiva no âmbito da legislação do ICMS.

As discussões fiscais entre os entes da Federação não são novidade no Brasil. Segundo estudos historiográficos, noticia-se que desde a República Velha haviam expedientes similares, sendo utilizados aquele tempo, agravamentos tributários ao invés de desonerações ${ }^{6}$. A situação caótica em relação ao ICMS foi ganhando maior expansão nas últimas décadas, especialmente pela ausência de políticas de "desenvolvimento nacional e regional eficientes e da perda da capacidade de investimentos públicos por parte do Governo Federal, e, sobretudo, por parte dos governos estaduais"7. Desta forma, as desonerações tributárias cedidas na esfera da legislação do ICMS passam, então, a demonstrar uma pauta absolutamente constante quanto não desejável à atração de investimentos de natureza privada.

O discurso político que justifica os programas de incentivo, no âmbito do ICMS, é, volta e meia, o desenvolvimento econômico-regional por meio de geração de emprego e renda. Ou seja, disputam-se investimentos privados à custa de receitas tributárias do ICMS. E quando nunca há estudos conscientes em que se avaliam se os custos aplicados - isto é, o impacto orçamentário das renúncias fiscais - são, de fato, compatíveis com os objetivos pretendidos ${ }^{8}$.

Para os Estados-membros, a perda global de arrecadação ${ }^{9}$ é resultado da utilização de providências de concorrência tributária predatória, fazendo com que os entes federados utilizem mecanismos que, por muitas vezes, acabam sendo prejudiciais para eles mesmos, num distúrbio fiscal traduzido por um páreo sem análise das consequências dessa corrida desenfreada e irresponsável ${ }^{10}$.

\footnotetext{
${ }^{5}$ BRASIL. Supremo Tribunal Federal. Repercussão Geral no Recurso Extraordinário n. 784.682. Relator: Ministro Marco Aurélio. DJ 25.4.2014.

${ }^{6}$ BERCOVICI, Gilberto. Desigualdades Regionais, Estado e Constituição. São Paulo: Max Limonad, 2003, p. 173.

${ }^{7}$ FARIA, Luiz Alberto Gurgel de. A extrafiscalidade e a concretização do princípio da redução das desigualdades regionais. São Paulo: QuartierLatin, 2010, p. 135.

${ }^{8}$ CORREIA NETO, Celso de Barros.; MONTENEGRO, Evanderson Pina.; CORDEIRO, Kamila de Araújo. A Guerra Fiscal em ICMS e o Papel do Supremo Tribunal Federal: precedentes e desafios atuais. Economic Analysis of Law Review. v. 9, n. 2, mai/jun. 2018, p. 37.

9 A renúncia fiscal tem impacto significativo na receita dos Estados. Nas lições de Szelbracikowski: "O Estado do Amazonas, por exemplo, no ano de 2016, teve uma perda relativa de receita na ordem de $-32,88 \%$. O Estado do Rio de Janeiro, também no ano de 2016, obteve decréscimos de receita no percentual de $-10,95 \%$ e estimativa de perda relativa de receita ainda maior para o ano de 2018 de $-12,09 \%$. No ano de 2016, os Estados da Bahia e Pernambuco tiveram as menores perdas relativas de receita, $-0,01 \%$ e $-0,88 \%$, respectivamente. Já o Estado de São Paulo obteve perda relativa de receita na ordem de $-7,45 \%$ no ano de 2016 , perspectiva de perda de $-7,48 \%$ para o ano corrente e projeção de perda relativa de $-7,51 \%$ para o ano de 2018. As perdas relativas de receitas da União, em razão da renúncia tributária, referentes aos anos de 2016, 2017 e 2018, são, respectivamente, -17,21\%, -16,86\% e -16,95\%" (SZELBRACIKOWSKI, Daniel. Guerra Fiscal do ICMS no Brasil: exame sobre a unanimidade exigida para a concessão de incentivos fiscais no Conselho Nacional de Política Fazendária (CONFAZ). 2016. 182 f. Dissertação (Mestrado em Direito). Escola de Direito de Brasília - EDB, Instituto Brasiliense de Direito Público - IDP, Brasília, 2016, p. 71).

${ }^{10}$ Segundo José Roberto Afonso "comparando montantes de receita entre União e Estados, em 2012, a renúncia dos estados que a informaram representou $15,6 \%$ da arrecadação do ICMS e equivalente a 1,2\% do PIB, enquanto a Receita
} 
Ainda, sob os olhares dos contribuintes, o resultado do incentivo concebido pelas desonerações vem, de forma genérica, carreado de insegurança jurídica, tanto no sentido da precariedade das vantagens com que lhes acometem os governos estaduais quanto pelo risco jurídico envolvido, diante da possibilidade de represálias que em discordância de si podem ser direcionadas por parte de outros Estados-membros ${ }^{11}$.

Ainda que a guerra fiscal na seara do ICMS não seja isolada no Brasil, conforme anteriormente exemplificado, tal embate diferencia-se por divulgar traços jurídicos particulares e estrutura constitucional específica. Logo, a concorrência entre os Estados configura-se juridicamente através do exercício de competência do artigo 155, inciso II, da Constituição Federal, que valida os Estados e o Distrito Federal a criar imposto sobre operações relativas à circulação de mercadorias. Valendo dessa incumbência legal e do fato de o modo de arrecadação desse imposto centralizar-se especialmente no Estado de origem, os Estados e o Distrito Federal engendram mecanismos de arranjos tributários, podendo-se destacar as isenções, os créditos presumidos, as reduções da base de cálculo, entre outras artimanhas - com o objetivo de remir os contribuintes para que "se instalem em seu território" $"$.

A prática tem restrições claras no nível do próprio texto constitucional que, no entanto, não são capazes de evitar a perpetuação da disputa. De acordo com a Constituição, o benefício fiscal não pode ser concedido sem observar o disposto no artigo $150, \S 6^{\circ}$, que exige lei específica, e também a previsão do artigo $155, \S 2^{\circ}$, XII, "g", que remete ao procedimento previsto em lei complementar, atualmente, a Lei Complementar n. 24/1975. Fora dessas hipóteses, a concessão é indevida e desrespeita a própria Constituição ${ }^{13}$.

Porém, tais apontamentos legislativos não são suficientes para barrar os conflitos. Desta forma, o Supremo Tribunal Federal é constantemente reclamado para realizar julgamentos aos embates federativos que englobam a licença de incentivos fiscais irregulares, da mesma forma que a pronunciar-se em relação aos efeitos dessas medidas nas vinculações com os particulares.

\footnotetext{
Federal estimou a sua renúncia para o mesmo ano em $20 \%$ da receita administrativa e equivalendo a $3,2 \%$ do PIB. As proporções se assemelham porque a receita administrada da União superava em 2,7 vezes o ICMS arrecadado pelos Estados, e essa também era a razão observada entre as duas renúncias - ou seja, benefícios igualmente elevados. Somados, se chega a uma renúncia agregada de 4,4\% do PIB". (AFONSO, José Roberto (Coord.). A renúncia tributária do ICMS no Brasil. Washington: Banco Interamericano de Desenvolvimento, 2014, p. 70).

${ }^{11}$ CARVALHO, Paulo de Barros. A concessão de isenções, incentivos ou benefícios fiscais no âmbito do ICMS. In: MARTINS, Ives Gandra da Silva; CARVALHO, Paulo de Barros. Guerra Fiscal: Reflexões sobre a concessão de benefícios fiscais no âmbito do ICMS. São Paulo: Noeses, 2012, p. 25).

${ }^{12}$ CORREIA NETO, Celso de Barros.; MONTENEGRO, Evanderson Pina.; CORDEIRO, Kamila de Araújo. A Guerra Fiscal em ICMS e o Papel do Supremo Tribunal Federal: precedentes e desafios atuais. Economic Analysis of Law Review. v. 9, n. 2, mai/jun. 2018, p. 38.

${ }^{13}$ Idem.
} 


\section{CONTROVÉRSIAS JURÍdICAS NO ÂMBITO DA GUERRA FISCAL DO ICMS: A EXIGÊNCIA DE CONVÊNIO NOS TERMOS NA LEI COMPLEMENTAR N. 24/1975 E O POSICIONAMENTO DO STF}

A guerra fiscal em relação ao ICMS é um fenômeno essencialmente federativo. Tal idiossincrasia, vinculada com a solidez do sistema tributário nacional e a concretude da Carta Magna das disposições ultrajadas, fazem com que o STF seja o local de predileção das disputas entre os entes subnacionais. Grande parte dos pleitos judiciais suscitados em relação à guerra fiscal e sua vinculação ao ICMS dizem respeito a questões de ordem constitucional, a demandar retorno em única e última instância do Supremo Tribunal Federal, em sede de controle de constitucionalidade, abstrato - nos casos de ADI, ADO ou ADPF, ou concreto - na propositura de recurso extraordinário. Logo, é na sede da Suprema Corte do Brasil que os Estados, por meio de ação direta, demandam a validade dos atos normativos através dos quais a guerra fiscal ganha seus contornos.

Os Estados prejudicados questionam, geralmente por meio de ação direta de inconstitucionalidade, benefícios fiscais concedidos por outros Estados ou pelo Distrito Federal de maneira unilateral, em desacordo com o artigo $155, \S 2^{\circ}$, XII, "g", do texto constitucional. O mais comum, é que o Tribunal seja provocado por Governadores insatisfeitos com a política fiscal predatória estabelecida por outros entes federados do mesmo nível ${ }^{14}$.

Tal questão pode ser observada na ADI 3794, de relatoria no Ministro Roberto Barroso, proposta pelo Governador do Estado do Paraná.

O representante do Estado suscitava pela inconstitucionalidade de artigos da Lei Complementar 93/01 do Estado do Mato Grosso do Sul, pelo fato de que o Estado na região central do Brasil permitia a concessão de incentivos fiscais e benefícios atrelados ao ICMS, sem amparo de convênio interestadual. O Governador do Paraná afirmava na ADI que a referida lei complementar instituía benefícios de natureza fiscal, extrafiscal e financeiro-fiscal, os quais eram aplicáveis especialmente aos empreendimentos industriais, afirmando que a vantagem concedida consistia na redução do saldo do ICMS, e poderia atingir até 77\% do valor do imposto devido. Ainda, sustentava o Governador do Paraná, que a redução da carga tributária estabelecida pelo governo do Mato Grosso do Sul foi concedida sem aparo em convênio interestadual, e, portanto, estava violando a Constituição Federal, sendo que o benefício fiscal havia sido concedido sem prévia autorização do CONFAZ (Conselho Nacional de Política Fazendária), violando o pacto federativo e fomentando a guerra fiscal

\footnotetext{
${ }^{14}$ AFONSO, José.; FUCK, Luciano Felício.; SZELBRACIKOWSKI, Daniel. Constitucionalidade das convalidações de incentivos fiscais acordadas entre os Estados. Revista Opinião Jurídica. Fortaleza, v. 14, 2016, p. 229.
} 
entre os Estados. O entendimento do STF foi pela inconstitucionalidade de alguns dos artigos da supracitada lei complementar, dando fim à estabelecida guerra fiscal entre os dois Estados ${ }^{15}$.

Embora incomum entre os pleitos ao STF, também existem ações diretas de inconstitucionalidade ajuizadas por outros legitimados constitucionais, como o Procurador-Geral da República ${ }^{16}$, entidades de classe de âmbito nacional ${ }^{17}$ e pelo Governador do próprio Estado de onde provém a lei questionada, normalmente, editada por iniciativa das Assembleias Estaduais ${ }^{18}$.

O julgamento de ações diretas de inconstitucionalidade, nas quais se discute a validade de benefícios fiscais concedidos unilateralmente, são as mais comuns suscitadas ao Supremo Tribunal Federal. Mas não é a única. A análise de julgados, das ações em tramitação e dos recursos de repercussão geral reconhecida permite identificar, alguns temas a respeito da guerra fiscal em ICMS submetidos ao STF, sendo, a exigência de convênio um dos mais dramáticos e comuns requerimentos.

As necessidades de convênio são geradoras de guerra fiscal de ICMS e que são reclamadas à Corte Magna do Brasil através de ações diretas de inconstitucionalidade, especialmente propostas por Governadores dos Estados. Nestas ações, são questionados atos normativos estaduais e distritais - leis ou atos normativos infralegais - que outorgam benesses tributárias de diferentes formas, sem que sejam respeitados os conclaves da Lei Complementar n. 24/1975, a qual dispões sobre os convênios para a concessão de isenções do imposto sobre operações relativas à circulação de mercadorias ${ }^{19}$.

A listagem de formas de benefícios fiscais englobada pelas ações é bastante ampla quanto o rol previsto no artigo $1^{\circ}$ da Lei Complementar n. 24/1975, o qual prevê isenções, reduções da base de cálculo, créditos presumidos, previsões de devolução de ICMS e qualquer outro incentivo fiscal ou financeiro-fiscal concedido na legislação desse imposto ${ }^{20}$.

Na ADI 1179, de relatoria do Ministro Carlos Velloso, por exemplo, o Tribunal discutiu a constitucionalidade da Lei n. 2.273/1994 do Estado do Rio de Janeiro que estabelecia prazo especial

\footnotetext{
15 BRASIL. Supremo Tribunal Federal. Ação Direta de Inconstitucionalidade n. 3794. Relator: Ministro Roberto Barroso. DJe 01.08.2011.

${ }^{16}$ Sobre a matéria, ADI 3246, Relator: Ministro Carlos Britto, DJe 01.09.2006.

${ }^{17}$ Sobre a matéria, ADI 4705, MC-REF, Relator: Ministro Joaquim Barbosa, DJe 18.06.2012.

${ }^{18}$ Sobre a matéria, ADI-MC 3936 MC, Relator: Ministro Gilmar Mendes, DJe 08.11.2007.

${ }^{19}$ CORREIA NETO, Celso de Barros.; MONTENEGRO, Evanderson Pina.; CORDEIRO, Kamila de Araújo. A Guerra Fiscal em ICMS e o Papel do Supremo Tribunal Federal: precedentes e desafios atuais. Economic Analysis of Law Review. v. 9, n. 2, mai/jun. 2018, p. 40.

${ }^{20}$ Leia-se o art. $1^{\circ}$ da Lei Complementar 24/1975: “As isenções do imposto sobre operações relativas à circulação de mercadorias serão concedidas ou revogadas nos termos de convênios celebrados e ratificados pelos Estados e pelo Distrito Federal, segundo esta Lei. Parágrafo único - O disposto neste artigo também se aplica: I - à redução da base de cálculo; II - à devolução total ou parcial, direta ou indireta, condicionada ou não, do tributo, ao contribuinte, a responsável ou a terceiros; III - à concessão de créditos presumidos; IV - à quaisquer outros incentivos ou favores fiscais ou financeirofiscais, concedidos com base no Imposto de Circulação de Mercadorias, dos quais resulte redução ou eliminação, direta ou indireta, do respectivo ônus; V - às prorrogações e às extensões das isenções vigentes nesta data".
} 
para pagamento de ICMS de cinco anos e ainda reduzia em $40 \%$ a correção monetária aplicável no período $^{21}$.

Em julgados como o acima referido, o STF tem orientação longínqua, no sentido de que a concessão unilateral de benefícios fiscais em matéria de ICMS, pelos Estados e pelo Distrito Federal, é inconstitucional. Para que haja validade, a lei deve atentar para o procedimento a que se refere o artigo 155, §2 , XII, “g”, da Constituição Federal, o qual indica deliberação obrigatória tanto dos Estados-membros quanto do Distrito Federal, na forma da lei complementar, para concessão e revogação de isenções, benefícios e incentivos em relação ao $\operatorname{ICMS}^{22}$.

Capitula-se que o estabelecimento de convênio continua sendo deliberado pela Lei Complementar n. 24/1975, mesmo após a promulgação da Carta Magna de 1988, uma vez que, nesses trinta anos, não houve edição de outra lei complementar que refletisse sobre a matéria ensejada. Para tanto, cabe destacar que a lei que atualmente está em vigor informa que benefícios fiscais irão ser concedidos pelos Estados ou pelo Distrito Federal, por meio de veredito unânime - conforme proclama o artigo $1^{\circ}$, o qual está transcrito na nota de rodapé n. 20, e revogados, pelo quórum de quatro quintos, de acordo com o artigo $2^{\circ}, \S 2^{\circ}$ da Lei Complementar n. 24/1975 23 . Sendo assim, qualquer Estado-membro e o Distrito Federal, se almejar implantar programas de benefícios fiscais em ICMS, "devem obter anuência dos demais entes no âmbito do Conselho Nacional de Política Fazendária" ${ }^{24}$. Portanto, a inexistência de convênio abala a validade da medida, conforme a consolidada jurisprudência do STF.

Interessante salientar que, ainda que a obrigatoriedade de anuência por parte dos demais Estados e do Distrito Federal, bem como o quórum de unanimidade não estejam expressos no Texto Maior, eles estão postos na Lei Complementar n. 24/1975. Nada obstante, a ausência de aprovação do CONFAZ não é tomada pelo STF tal qual forma de ofensa reflexa, o que inibiria o conhecimento das ações diretas de inconstitucionalidade. É compreendida como desacato direto ao disposto no artigo 155, §2º, XII, “g”, da Constituição Federal ${ }^{25}$.

Neste sentido, o Supremo Tribunal Federal tem entendimento consolidado em relação à temática e, ao que tudo aponta, não há indícios de alterações breves em relação a esse ponto. Assim

\footnotetext{
${ }^{21}$ BRASIL. Supremo Tribunal Federal. Ação Direta de Inconstitucionalidade n. 1179. Relator: Ministro Celso Velloso. DJ 19.12.2002.

${ }^{22}$ AFONSO, José.; FUCK, Luciano Felício.; SZELBRACIKOWSKI, Daniel. Constitucionalidade das convalidações de incentivos fiscais acordadas entre os Estados. Revista Opinião Jurídica. Fortaleza, v. 14, 2016, p. 235.

${ }^{23}$ Leia-se o art. $2^{\circ}, \S 2^{\circ}$ da Lei Complementar 24/1975: Art. $2^{\circ}$ - Os convênios a que alude o art. $1^{\circ}$, serão celebrados em reuniões para as quais tenham sido convocados representantes de todos os Estados e do Distrito Federal, sob a presidência de representantes do Governo federal. $\S 2^{\circ}$ - A concessão de benefícios dependerá sempre de decisão unânime dos Estados representados; a sua revogação total ou parcial dependerá de aprovação de quatro quintos, pelo menos, dos representantes presentes.

${ }^{24}$ CORREIA NETO, Celso de Barros.; MONTENEGRO, Evanderson Pina.; CORDEIRO, Kamila de Araújo. A Guerra Fiscal em ICMS e o Papel do Supremo Tribunal Federal: precedentes e desafios atuais. Economic Analysis of Law Review. v. 9, n. 2, mai/jun. 2018, p. 40.

${ }^{25}$ Idem.
} 
sendo, para a Suprema Corte do Brasil, concedidas na ausência de procedimento que esteja de acordo com a Lei Complementar n. 24/1975, as benesses tributárias na legislação do ICMS são consideradas inconstitucionais ${ }^{26}$.

Porém, entre os precedentes do Supremo Tribunal Federal, há um caso de não declaração de inconstitucionalidade de lei estadual que concedia exoneração tributária na ausência de procedimento adequado e em consonância com a lei complementar. Cuida-se da ADI 3421, de relatoria no Ministro Marco Aurélio, na qual discutia-se a legalidade da Lei Estadual n. 14.586/2004, do Estado do Paraná, a qual "proíbe a cobrança de ICMS nas contas de serviços públicos estaduais à igrejas e templos de qualquer culto" ${ }^{27}$. Na ocasião, por unanimidade dos votos, o Plenário do Supremo Tribunal Federal julgou improcedente a Ação Direta de Inconstitucionalidade, uma vez que admitiu que, para o caso em específico, havia necessidade de análise particular quanto à matéria pleiteada pelo Estado do Paraná ${ }^{28}$.

De outro vértice, destaca-se o entendimento trazido por Carlos Campos ${ }^{29}$ o qual grifa que o Tribunal, em grande parcela dos casos em que toma decisões em relação a benefícios fiscais em ICMS, cinge-se à mera análise formal do texto de lei de incentivo, apresentando apenas se o "ato normativo impugnado foi precedido da celebração de convênio interestadual. A falta de convênio é tomada como razão suficiente para a declaração da inconstitucionalidade da lei”. Ainda, para Carlos Campos

no caso da lei paranaense, fugindo à regra, a Corte concedeu interpretação teleológica à regra do art. 155, §2, XII, "g”, da Constituição, para restringir seu alcance a casos em que a exoneração fiscal concedida represente, de fato, como instrumento de disputa federativa ${ }^{30}$.

\footnotetext{
${ }^{26}$ Ibidem, p. 41.

${ }^{27}$ BRASIL. Supremo Tribunal Federal. Ação Direta de Inconstitucionalidade n. 3421. Relator: Ministro Marco Aurélio. DJe 28.05.2010

${ }^{28}$ Considerações pertinentes à ADI 3421: “A disciplina legal em exame apresenta peculiaridade e merece reflexão para concluir estar configurada ou não a denominada guerra fiscal”, ressaltou o ministro Marco Aurélio, relator, no início de seu voto. Ele destacou que, conforme o artigo 150, inciso VI, alínea "b", da Constituição Federal, os templos de qualquer culto estão imunes a impostos. Com base no parágrafo $4^{\circ}$, do citado artigo, o ministro afirmou que a isenção limita-se ao patrimônio, à renda e aos serviços relacionados com as finalidades essenciais das entidades nela mencionadas. O ministro Marco Aurélio ressaltou que a lei complementar relativa à disciplina da matéria é a 24/75. "Nela está disposto que as peculiaridades do ICMS - benefícios fiscais - hão de estar previstos em instrumento formalizado por todas as unidades da federação", disse. De acordo com ele, a disciplina não revela isenção alusiva a contribuinte de direito, isto é, aquele que esteja no mercado, mas a contribuinte de fato, "de especificidade toda própria", presentes igrejas e templos de qualquer crença quanto à serviços públicos estaduais próprios, delegados, terceirizados ou privatizados de água, luz, telefone e gás. O relator salientou que a proibição de introduzir benefício fiscal sem o assentimento dos demais estados tem como causa evitar competição entre as unidades da federação e, conforme o ministro Marco Aurélio, isso não acontece na hipótese. "Está-se diante de opção político-normativa possível, não cabendo cogitar de discrepância com as balizas constitucionais referentes ao orçamento, sendo irrelevante o cotejo buscado com a lei de responsabilidade fiscal, isso presente o controle abstrato de constitucionalidade", disse.

"No caso, além da repercussão quanto à receita, há o enquadramento da espécie na previsão da primeira parte do parágrafo $6^{\circ}$ do artigo 150, da Carta Federal, o que remete a isenção à lei específica", ressaltou o relator".

Disponível em: http://www.stf.jus.br/portal/cms/verNoticiaDetalhe.asp?idConteudo=125923. Acesso em: 19/10/2018.

${ }^{29}$ CAMPOS, Carlos Alexandre de Azevedo. ADI 3421: releitura da "guerra fiscal do ICMS". In: HORBACH, Beatriz Bastide; FUCK, Luciano Felício. (Org.). O Supremo por seus Assessores. São Paulo: Almedina, 2014, p. 225.

${ }^{30}$ Ibidem, p. 229.
} 
Em ferrenha crítica ao posicionamento do Tribunal, Carlos Campos, defende uma interpretação mais íntima do conceito de guerra fiscal, afastando-se do pensamento formalista, de modo a "assegurar a harmonia do federalismo fiscal, sem amesquinhar a possibilidade de os estados promoverem, quando do uso da função extrafiscal do imposto, valores políticos e sociais que a ordem constitucional reconheça relevantes" ${ }^{31}$.

Ricardo Lodi Ribeiro apresenta pensamento semelhante ao de Carlos Campos. Segundo Ricardo Lodi Ribeiro, a manutenção da autonomia local deve ser delimitada apenas quando houver risco à preservação do federalismo fiscal e não para a integralidade das exonerações fiscais concedidas aos Estados. Neste sentido, afirma que os "benefícios fiscais vinculados à exploração de atividade que, pelas suas características, não poderia ser efetivada em outro Estado, como a extração mineral, por exemplo". Neste diapasão, "os benefícios concedidos por outros Estados não teriam o condão de afastar o empreendedor do local onde a operação precisa ser desenvolvida, não havendo que se falar em guerra fiscal ensejadora da limitação da autonomia local"32.

Porém, embora haja crítica da doutrina, o posicionamento do STF é contrário. O precedente estabelecido na ADI 3421, embora possa ser impulsionador para apreciação para se definir o cerne e a abrangência das regras que restringem a concessão de benefícios fiscais quando fala-se de ICMS, não parece apontar precisamente uma reanálise da orientação atual da Corte Maior, sendo assim, a compreensão é idêntica: as exonerações unilaterais na legislação de ICMS são inválidas ${ }^{33}$.

\section{EXIGÊNCIA DE UNANIMIDADE PARA CONCESSÃO DE BENEFÍCIOS FISCAIS EM ICMS E O EMBATE DO SUPREMO TRIBUNAL FEDERAL}

Destacado no capítulo 2, a forma mais usual de atuação do STF ocorre por meio de ações diretas de inconstitucionalidade, nas quais são discutidos a validade de benefícios fiscais concedidos unilateralmente. Porém, como previamente enfatizado, sabe-se que tal requerimento não é único, contemplando um rol exaustivo de temas em relação à guerra fiscal em ICMS que são encaminhados para a Corte Magna.

Objetivando uma análise didática, optou-se por enfatizar no capítulo anterior o mais comum dos requerimentos, qual seja, a súplica em relação à exigência de convênio, nos termos da Lei Complementar n. 24/1975, para concessão de benefícios fiscais em matéria de ICMS. Superadas

\footnotetext{
${ }^{31}$ Ibidem, p. 230.

${ }^{32}$ RIBEIRO, R. L. Súmula contra guerra fiscal pode cristalizar desigualdade. São Paulo: Consultor Jurídico, v.1, 2012 , p. 8.

${ }^{33}$ CORREIA NETO, Celso de Barros.; MONTENEGRO, Evanderson Pina.; CORDEIRO, Kamila de Araújo. A Guerra Fiscal em ICMS e o Papel do Supremo Tribunal Federal: precedentes e desafios atuais. Economic Analysis of Law Review. v. 9, n. 2, mai/jun. 2018, p. 41.
} 
as anotações relativas a esse tema, passa a ser destacada outra proposição suscitada à Suprema Corte do Brasil no que tange à guerra fiscal em ICMS: a exigência de unanimidade para concessão de benefícios.

Entre as ações que ainda aguardam julgamento no STF está a Arguição de Descumprimento de Preceito Fundamental n. 198, ajuizada pelo Governador do Distrito Federal, em relação aos artigos $2^{\circ}, \S 2^{\circ}$, e $4^{\circ}$ da Lei Complementar n. 24/1974, que preveem deliberação unânime para concessão de benefícios físcais em matéria de ICMS e ratificação tácita dos convênios, se transcorrido in albis o prazo legal ${ }^{34}$.

Na exordial, discute-se que a unanimidade para concessão de benefícios fiscais está em desacordo, violando o princípio democrático da autonomia dos entes federativos, bem como o princípio da proporcionalidade. A providência uníssona, conforme proclama o requerente, desrespeita a vontade da maioria, uma vez que fornece para qualquer Estado-membro a possibilidade de impor unilateralmente sua vontade, através do poder de veto que a exigência da votação cônsona provoca ${ }^{35}$.

Nesta toada, os argumentos do requerente informam que a unanimidade não é uma exigência trazida na Carta Magna de 1988 para qualquer aprovação de ordem legislativa, nem sequer para alteração do texto constitucional, que exige três quintos dos votos dos membros de cada uma das Casas legislativas, conforme dispõe o artigo 60, §2 da Constituição Federal de 1988. Logo, a promoção de decisão única, não promove a harmonização ou o diálogo entre os entes federativos, mas estimula a guerra fiscal ${ }^{36}$.

Cabe ressaltar que o mérito de tal ação, até o presente momento, não deliberou decisão na Corte Superior. Em sede liminar, foi indeferida monocraticamente pelo relator, Ministro Dias Toffoli, no ano de 2009, por meio do fundamento de que "os artigos objeto da [...] ação encontramse em vigor há mais de trinta e quatro anos, sendo certo que, vinte e um desses anos, decorreram já sob a égide da Constituição Federal de $1988^{\prime 37}$, enfatizando, ainda, que o STF vem aplicando a lei há anos, conforme podem ser visualizados os precedentes do Tribunal.

Na ADPF n. 198, pode-se afirmar, em síntese, que a Corte se vê diante de três caminhos de
interpretação. O primeiro é declarar que a exigência de unanimidade simplesmente é
incompatível com a ordem constitucional em vigor e, por conseguinte, não foi recepcionada.
Isso significa que o quórum de unanimidade estaria fora da margem de discricionariedade
política do legislador, e, por isso, não pode ser adotado pela legislação editada com base no
art. 155 , §2, XII, "g", da Constituição. O segundo é adotar a orientação radicalmente oposta
e entender que a unanimidade não apenas é compatível como a Constituição em vigor, mas
é, na verdade, obrigatória, por conta do perfil nacional do ICMS. Seria inválido, segundo

\footnotetext{
${ }^{34}$ CORREIA NETO, Celso de Barros.; MONTENEGRO, Evanderson Pina.; CORDEIRO, Kamila de Araújo. A Guerra Fiscal em ICMS e o Papel do Supremo Tribunal Federal: precedentes e desafios atuais. Economic Analysis of Law Review. v. 9, n. 2, mai/jun. 2018, p. 43.

35 Idem.

36 Idem.

37 BRASIL. Supremo Tribunal Federal. Arguição de Descumprimento de Preceito Fundamental. Decisão Monocrática. Relator: Ministro Dias Toffoli. DJe 24.11.2009.
} 
essa leitura, a escolha de qualquer outro quórum de deliberação. A terceira via é intermediária. Toma a exigência de deliberação unânime como uma das opções legislativas válidas que podem ser adotadas pelo legislador. Não é obrigatória nem proibida ${ }^{38}$.

A leitura realizada por Martins e Carvalho sobre a temática vai de encontro com a segunda via - ou seja, a validação da unanimidade como imposição constitucional. A sustentação desta tese baseia-se em parecer elaborado em resposta à consulta da Secretaria da Fazenda do Governo do Estado de São Paulo e a Federação do Comércio de Bens, Serviços e Turismo do Estado de São Paulo - Fecomercio ${ }^{39}$. O autor defende que a unanimidade posta na Lei Complementar n. 24/1975 é decorrência da "vocação nacional" do ICMS, no enquadramento da Constituição Federal de 1988. Decorre, desta forma, da matéria constitucional das alíquotas dos ICMS, que estão previstas no artigo 155, §2 $2^{\circ}$ IV, V e VI, da Carta Magna. Em suas lições, o autor interpreta que na colocação "salvo deliberação em contrário dos Estados e do Distrito Federal”, constante no inciso VI ${ }^{40}$, a imposição de que a anuência de todos os Estados e do Distrito Federal seria obrigatória para a adoção de alíquotas internas inferiores àquelas previstas para as operações interestaduais ${ }^{41}$.

Ainda, compreende, da mesma forma, que apenas à União seria detentora do poder em relação à disposição sobre política de desenvolvimento regional, fundamentando seu argumento no texto do artigo 151, I, da Carta Maior, que impossibilita o emprego de tributo que interfira na predileção em favor de Estado, Município ou Distrito Federal, mas faz uma exceção quanto a “concessão de incentivos fiscais destinados a promover o equilíbrio do desenvolvimento socioeconômico entre as diferentes regiões do País"42.

Martins e Carvalho concluem que a exigência da unanimidade seria uma decorrência da própria forma federativa e estaria, portanto, sob a proteção da cláusula pétrea prevista no artigo 60, $\S 4^{\circ}$, I, da Constituição Federal de 1988, que impede emendas tendentes a abolir "a forma federativa de Estado". O discurso legislativo, de acordo com este posicionamento, estaria retido em relação ao quórum legislativo, que não poderia ser outro senão o de anuência absoluta e unânime ${ }^{43}$.

Em contraposição ao pensamento apresentado por Martins e Carvalho estão as anotações de Ferraz Junior, o qual publica que "a Constituição não exige consenso unânime nem a unanimidade é a hipótese mais adequada ao Estado Democrático de Direito em que se constitui a República

\footnotetext{
${ }^{38}$ CORREIA NETO, Celso de Barros.; MONTENEGRO, Evanderson Pina.; CORDEIRO, Kamila de Araújo. A Guerra Fiscal em ICMS e o Papel do Supremo Tribunal Federal: precedentes e desafios atuais. Economic Analysis of Law Review. v. 9, n. 2, mai/jun. 2018, p. 43 - 44.

${ }^{39}$ MARTINS, Ives Gandra da Silva. CARVALHO, Paulo de Barros. Guerra Fiscal: Reflexões sobre a concessão de benefícios fiscais no âmbito do ICMS. São Paulo, Noeses, 2012.

${ }^{40}$ Transcrição da redação do artigo 155, §2 , VI, da Constituição de 1988: "salvo deliberação em contrário dos Estados e do Distrito Federal, nos termos do disposto no inciso XII, "g", as alíquotas internas, nas operações relativas à circulação de mercadorias e nas operações de serviços, não poderão ser inferiores às previstas para as operações interestaduais".

${ }^{41}$ MARTINS, Ives Gandra da Silva. CARVALHO, Paulo de Barros. Guerra Fiscal: Reflexões sobre a concessão de benefícios fiscais no âmbito do ICMS. São Paulo, Noeses, 2012.

${ }^{42}$ Idem.

${ }^{43}$ Idem.
} 
Federativa"44. Nas lições do autor, a exigência de unanimidade "desequilibra a relação econômica entre as unidades federadas, na medida em que engessam e solidificam as desigualdades ao emperrar as mudanças" 45 . Logo, não se viabiliza o diálogo e o concerto entre os entes federados, mas "torna-o impossível ao perverter o sentido da relação regra/exceção: torna-se regra excepcionar (vetar) o que contraria a adesão de todos; é o que acaba por fazer da deliberação conjunta uma espécie de regra sem exceção: ou é unânime ou não existe, é nula" ${ }^{46}$.

Contempla deste mesmo pensamento o autor Fernando Scaff, o qual indica que a unanimidade decisória no CONFAZ seria um "contrabando normativo autoritário", que persiste no ordenamento jurídico brasileiro como resíduo de um recorte histórico autoritário, felizmente superado com a promulgação da Constituição Federal de $1988^{47}$. Ocupa-se da única regra de aprovação unânime no direito brasileiro. A norma permite que qualquer Estado, isoladamente, tenha a possibilidade de impedir um debate em virtude de programas de incentivo vitais para determinada região do Brasil, indo em desacordo com o princípio federativo e o princípio democrático ${ }^{48}$.

No aguardo pelo julgamento da ADPF n. 198, o Congresso Nacional debate a modificação em relação ao quórum de deliberação do CONFAZ para a permissão da promoção de benefícios fiscais. O tema foi matéria do Projeto de Lei Complementar n. 238 de 2013, do Poder Executivo, mas não integrou a redação final da tese que foi transformada na Lei Complementar $\mathrm{n}$. 148/2014, que estabelece normas de finanças públicas voltadas para a responsabilidade na gestão fiscal e dispõe sobre critérios de indexação dos contratos de refinanciamento da dívida celebrados entre a União, Estados, o Distrito Federal e Municípios ${ }^{49}$.

A matéria do quórum de votação, para a remissão de créditos e reinstituição de benefícios fiscais, foi, da mesma forma, objeto de Projeto de Lei Complementar n. 130/2013, de autoria da Senadora Lucia Vânia, representante do Estado de Goiás pelo Partido Socialista Brasileiro. Aprovado no Senado Federal, tramitou na Câmara dos Deputados como Projeto de Lei Complementar n. 54/2015, dando lugar à Lei Complementar n. 160/2017, afastando o quórum da unanimidade da Lei Complementar n. 24/1975, passando a dispor sobre convênio que permite aos Estados e ao Distrito Federal deliberar sobre a remissão dos créditos tributários, constituídos ou não, decorrentes das isenções, dos incentivos e dos benefícios fiscais ou financeiro-fiscais instituídos em desacordo com

\footnotetext{
${ }^{44}$ FERRAZ JUNIOR, Tercio Sampaio. Unanimidade ou maioria nas deliberações do CONFAZ: considerações sobre o tema a partir do princípio federativo. Revista Fórum de Direito Tributário - RFDT, Belo Horizonte, ano 10, n. 59, set./out. 2012, p. 9.

${ }^{45}$ Ibidem, p. 10.

${ }^{46}$ Ibidem, p. $10-11$.

${ }^{47}$ SCAFF, Fernando Facury. Guerra fiscal e súmula vinculante: entre o formalismo e o realismo. In: ROCHA, Valdir de Oliveira (coord.). Grandes Questões atuais do Direito Tributário. v. 18. São Paulo: Dialética, 2014, p. 90.

${ }^{48}$ Ibidem, p. 95.

${ }^{49}$ CORREIA NETO, Celso de Barros.; MONTENEGRO, Evanderson Pina.; CORDEIRO, Kamila de Araújo. A Guerra Fiscal em ICMS e o Papel do Supremo Tribunal Federal: precedentes e desafios atuais. Economic Analysis of Law Review. v. 9, n. 2, mai/jun. 2018, p. 45.
} 
o disposto na alínea "g" do inciso XII do $\S 2^{\circ}$ do art. 155 da Constituição Federal e a reinstituição das respectivas isenções, incentivos e benefícios fiscais ou financeiro-fiscais ${ }^{50}$.

$\mathrm{O}$ artigo $2^{\circ}$ da Lei de 2017 estabelece que o convênio seja aprovado e ratificado com o voto favorável de, no mínimo, dois terços das unidades federadas e um terço das unidades federadas integrantes de cada uma das cinco regiões do Brasil. Esse quórum, porém, aplica-se apenas nas possibilidades de remissão dos créditos tributários constituídos em decorrência de benefícios irregulares e reinstituição dos referidos benefícios, não substituindo, portanto, o quórum estabelecido pela Lei Complementar n. 24/1975, que segue em vigor para os demais casos ${ }^{51}$. Sendo assim, para uma mudança paradigmática diante desta matéria, os tributaristas contrários ao atual posicionamento do Supremo Tribunal Federal, seguem aguardando posicionamentos inovadores.

\section{CONSIDERAÇÕES FINAIS}

O Supremo Tribunal Federal tem papel de extrema relevância à matéria da guerra fiscal no Brasil, especialmente no que conserve às deliberações vinculadas ao ICMS, uma vez que, tal qual demonstrado, é o tributo que causa maiores questionamentos e demandas à Corte Superior nesse embate entre os entes da federação.

Embora trabalhe há décadas com as questões relativas à guerra fiscal, pela grande abertura de matérias relativas ao tema, o Tribunal não tomou frente para solucionar ou dar melhores condições às questões suscitadas e que, por diversas vezes, permanecem com a mesma interpretação desde 1975, ou seja, há mais de trinta e três anos, o que, claramente, agrava e o quadro dos conflitos de incentivos fiscais irregulares, o que impede um equilíbrio da ordem tributária pertinente ao ICMS. Em uma declaração deveras popular, poder-se-ia dizer que a Corte Magna permite que os Estados-membros e o Distrito Federal tratem a questão como um leilão: quem oferece mais, leva o prêmio; sem quaisquer considerações das consequências jurídicas e econômicas que esse não posicionamento enfático pode causar, especialmente, aos entes privados e à economia do País.

Ademais à orientação do STF esteja pautada na inconstitucionalidade da concessão unilateral de incentivos fiscais em matéria de ICMS, a atuação do Tribunal parece, até hoje, insuficiente para debater o conflito federativo em curso.

A indicação, tal qual demonstrada com a aprovação da Lei Complementar n. 160/2017, o posicionamento do Supremo Tribunal Federal preocupa-se em acelerar e enrijecer as medidas de combate à concessão unilateral de novos incentivos fiscais, mas sem solucionar as situações já sólidas no tempo.

\footnotetext{
${ }^{50}$ Idem.

${ }^{51}$ Idem.
} 
Assim, o enquadramento geral parece apontar que a defrontação da guerra fiscal, tal qual um embate federativo que é, precisa de ordenação de azáfamas entre os diferentes integrantes da federação, em especial, o diálogo na seara legislativa. Logo, aguardar posicionamentos da Suprema Corte do Brasil, é pretender do Poder Judiciário muito do que ele pode e quer ofertar.

\section{REFERÊNCIAS}

AFONSO, José Roberto (Coord.). A renúncia tributária do ICMS no Brasil. Washington: Banco Interamericano de Desenvolvimento, 2014.

.; FUCK, Luciano Felício.; SZELBRACIKOWSKI, Daniel. Constitucionalidade das convalidações de incentivos fiscais acordadas entre os Estados. Revista Opinião Jurídica. Fortaleza, v. 14, 2016.

BERCOVICI, Gilberto. Desigualdades Regionais, Estado e Constituição. São Paulo: Max Limonad, 2003.

BRASIL Supremo Tribunal Federal. Arguição de Descumprimento de Preceito Fundamental n. 190. Relator: Ministro Edson Fachin. DJ. 12.05.2017.

19.12.2002.

Ação Direta de Inconstitucionalidade n. 1179. Relator: Ministro Celso Velloso. DJ

. Ação Direta de Inconstitucionalidade n. 3421. Relator: Ministro Marco Aurélio. DJe 28.05.2010.

DJe 01.08.2011.

Ação Direta de Inconstitucionalidade n. 3794. Relator: Ministro Roberto Barroso.

Arguição de Descumprimento de Preceito Fundamental. Decisão Monocrática. Relator: Ministro Dias Toffoli. DJe 24.11.2009.

Aurélio. DJ 25.4.2014.

Repercussão Geral no Recurso Extraordinário n. 784.682. Relator: Ministro Marco

CAMPOS, Carlos Alexandre de Azevedo. ADI 3421: releitura da "guerra fiscal do ICMS". In: HORBACH, Beatriz Bastide; FUCK, Luciano Felício. (Org.). O Supremo por seus Assessores. São Paulo: Almedina, 2014.

CARVALHO, Paulo de Barros. A concessão de isenções, incentivos ou benefícios fiscais no âmbito do ICMS. In: MARTINS, Ives Gandra da Silva; CARVALHO, Paulo de Barros. Guerra Fiscal: Reflexões sobre a concessão de benefícios fiscais no âmbito do ICMS. São Paulo: Noeses, 2012.

CORREIA NETO, Celso de Barros. O avesso do tributo. 2 ed. São Paulo: Almedina, 2016. 
FARIA, Luiz Alberto Gurgel de. A extrafiscalidade e a concretização do princípio da redução das desigualdades regionais. São Paulo: QuartierLatin, 2010.

MONTENEGRO, Evanderson Pina.; CORDEIRO, Kamila de Araújo. A Guerra Fiscal em ICMS e o Papel do Supremo Tribunal Federal: precedentes e desafios atuais. Economic Analysis of Law Review. v. 9, n. 2, mai/jun. 2018.

FERRAZ JUNIOR, Tercio Sampaio. Unanimidade ou maioria nas deliberações do CONFAZ: considerações sobre o tema a partir do princípio federativo. Revista Fórum de Direito Tributário - RFDT, Belo Horizonte, ano 10, n. 59, set./out. 2012.

MARTINS, Ives Gandra da Silva. CARVALHO, Paulo de Barros. Guerra Fiscal: Reflexões sobre a concessão de benefícios fiscais no âmbito do ICMS. São Paulo, Noeses, 2012.

RIBEIRO, R. L. Súmula contra guerra fiscal pode cristalizar desigualdade. São Paulo: Consultor Jurídico, v.1, 2012.

SCAFF, Fernando Facury. Guerra fiscal e súmula vinculante: entre o formalismo e o realismo. In: ROCHA, Valdir de Oliveira (coord.). Grandes Questões atuais do Direito Tributário. v. 18. São Paulo: Dialética, 2014.

SZELBRACIKOWSKI, Daniel. Guerra Fiscal do ICMS no Brasil: exame sobre a unanimidade exigida para a concessão de incentivos fiscais no Conselho Nacional de Política Fazendária (CONFAZ). 2016. 182 f. Dissertação (Mestrado em Direito). Escola de Direito de Brasília - EDB, Instituto Brasiliense de Direito Público - IDP, Brasília, 2016. 